\title{
Fundamental Analysis Vs Technical Analysis in The Egyptian Stock Exchange - Empirical Study
}

\author{
[Ahmed. S. Wafi ${ }^{\mathrm{a}}$, Hassan Hassan ${ }^{\mathrm{b}}$, Adel Mabrouk ${ }^{\mathrm{c}}$ ]
}

\begin{abstract}
This Study aims at attempting to answer the following question: Which of the Analysis Methods i.e. technical analysis or fundamental analysis has more credibility in forecasting the value (prices \& returns) of the share?. To achieve this objective, the study used the Pooled CrossSectional and Time Series Analysis. In this paper, we have applied on an arbitration sample consisting of (37) nonfinancial companies listed in the Egyptian Financial Markets (The Egyptian Exchange EGX) and which represent the most active companies in EGX through the Period (1998 - 2009) i.e. yearly periods. The results show that there is a significant difference between the results of the technical analysis and the fundamental analysis concerning the value (prices \& returns) of the share in EGX in favor of the technical analysis method, that is a result of the characteristics of the Egyptian market which is inefficient financially, and the variation in financial reports and statements, in addition to the impact of the noneconomic aspects. This result matches with some of the studies which were applied in the emerging financial markets.
\end{abstract}

Keywords-Fundamental Analysis; Technical Analysis; Stock Value; Efficient Market; Emerging Market.

\section{Introduction}

There are pioneering methods to analyze the shares in the scope of investment decisions. Nevertheless, We found the scope of using these tools has double points of view i.e. the professional investors versus non-professional investors, and buying versus selling. The important question is: Which of the used methods is more credible in forecasting the value of the shares in the stock market? To answer this question, we must test the forecasting potentiality of the used methods to differentiate between them and hence, we find out that forecasting is among the very precise subjects [6].

${ }^{\mathrm{a}}$ Ahmed Soliman Ahmed Soliman Wafi

Faculty of Commerce - Cairo University Egypt

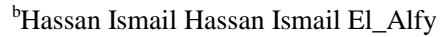
Faculty of Commerce - Cairo University Egypt
}

${ }^{\mathrm{c}}$ Adel Mabrouk Mohammed

Faculty of Commerce - Cairo University Egypt
It is possible to face the problem of forecasting in the movement of shares prices through two approaches: Fundamental Analysis \& Technical Analysis. Due to the rise in the rate of variance in the stock market, then the forecasting function in the future trend of the stock prices, is considered as a very accurate function [23].

\section{Importance of the Study}

The importance of this study is that it is an academic attempt to highlight which result of these methods is more credible, the results of the technical analysis or the results of the fundamental analysis for the prices and the returns shares? This can be done through a comparison between the results of technical analysis and fundamental analysis by applying on the Egyptian stock market. This helps in assisting the professional and non-professional investors, the portfolio's managers, and managers of the securities brokerage companies to apply the best method of analyzing the stock movement in the Egyptian Stock markets.

\section{Research Problem}

The Study attempts to solve the study problem, which can be formulated as follows:

Which of the method of analysis of stock movement techniques (technical analysis or fundamental analysis) is more credible in its results for using to predict values (prices and returns) of shares in the Egyptian stock market?

\section{Hypotheses}

The Study Hypotheses are represented in the following two main hypotheses:

1. There is No significant difference between the technical analysis results and the fundamental analysis results concerning the stock price.

2. There is No significant difference between the technical analysis results and the fundamental analysis results concerning the stock return.

\section{v. Theoretical Background and Literature Review}

The investor who transacts in the stock exchange, attempts to find a new and good scientific method which 
satisfies his investment objectives, in order to be able to take the investment decisions. It has the following two methods for taking any investment decision in the stock market: Fundamental Analysis and Technical Analysis, which are presented as follows:

\section{A. Fundamental Analysis Approach}

1) There are different and varying concepts related to the fundamental analysis, but they all agree on one objective. Therefore, the fundamental analysis can be defined as "A Science which has its fixed bases and steps to achieve its objectives in specifying the intrinsic value of the share in the stock market, through a general framework which takes the form of studying the expected economical forecasts reaching the sectors from which we expect an increase in the sales and profits. Consequently, the strength of the companies is studied financially based on the historical financial information and their current conditions and measuring the efficiency of their management, and their commercial opportunities reaching specifying the intrinsic value of shares. This is followed by comparing them with the market values resulting from the interactions between the demand and supply to determine the investments opportunities (profits or losses)" [8, 9, 22].

\section{B. Technical Analysis Approach}

There are many disparate points of views for many researchers and professionals as: Merphy [16], Fontanills \& Gentile [9], Thomsett, [22], Edwards \& Magee [7], and Chen [4]. We summarize these disparate points of views to express the technical analysis as: "A Study of movements of past and current prices in a financial market which may help in specifying the trend in the future".

\section{Technical Analysis versus Fundamental Analysis}

Lo, et al., [14] stated that the technical analysis may be suitable as one of the effective means in extracting useful information from the market, where the differences between the technical and the fundamental analysis, can be summarized as follows:

1. Both use different types of historical information, where the fundamental approach uses the information related to stock dividend, sales, income, and other rates, whereas the technical analysis uses just simple information such as price and the volume factors.

2. The Fundamental Analysis looks at the shares prices linked to the intrinsic value, and comparing it with the market value to reach whether it is estimated at less than its intrinsic value i.e. (Undervalued) or whether it is (Overvalued), but the technical analysis depends on the prices and trends.
3. Methods of the Fundamental Analysis are applied for long periods of time (i.e. years) to become more credible in their results; whereas the technical analysis strategies are applied in short term periods (i.e. hours, days, weeks, months) so that their results will have better credibility.

4. The Technical Analysis is more sensitive to changes in prices, where they can produce many signals (buying or selling during the daily trading).

It is clear that both the Technical Analysis and the Fundamental Analysis Methods which specialize in forecasting the future status of the market - solving the same problem i.e. specifying the trend of prices, which the market is expected to move towards. The only difference is that each of these two methods attempts to get nearer to solve this problem from a different point of view [17].

Murphy [17] believes that if the fundamental analysis is reflected in the market price, then there is no necessity to study these fundamental analyses. So that, reading the graph becomes "As one of the Technical Analysis Tools" which is a summarized model of fundamental analysis. The contrast can't be correct where the fundamental analysis does not include a study of the movement of the price "Nature of the Technical Analysis". Consequently, we can only use the technical analysis method for trading in the stock exchange. At the same time we can't rely on the fundamental analysis method alone without taking into consideration the technical analysis in the market.

As a consequence of this, there are various opinions in terms of selecting one method or in terms of adding them. According to Murphy [17] illustrated that if the investor has to select only one of the two methods, then the logical selection is "Technical Analysis" Approach Afterwards, the analyst has to take the following step in reaching a conclusion on how those expected events which will influence the markets. This is in reverse of the technical analysis, which has one step only, which it takes, where the reflection of information in the market. The Technical Analysis studies the market which gives it an advantage feature to many in the financial world. In a different direction as Goumatianos [11] pointed out that the technical and fundamental analysis, are complementary strategies for investment.

By reviewing the previous literature, we find two types of studies testing the credibility of technical analysis and fundamental analysis in the various financial markets. The first type depends on a survey study, in Lui \& Mole [15] study was aimed to attempt to reach a method of evaluation to develop forecasts of the movement of the exchange rate in the foreign exchange market in Hong Kong. The results of this study show that less than $85 \%$ of the responders based on both the Technical analysis and Fundamental Analysis to expect the movement of the exchange rate in the future on the various range; whereas on the short-term, there is a different trend to rely on the technical analysis as opposed to the Fundamental Analysis. This is reached by Oberlechner [19] study was aimed at studying the importance of the Fundamental Analysis \& Technical Analysis between the 
foreign exchange dealers and the financial journalists. The results proved that most traders use all the technical and fundamental expectation trends; and whenever the scope of expectations is short, the more important the technical analysis is. The results show that the importance of the technical analysis may increase over the decades.

In a somewhat contrasting context, there is a study by Venkatesh \& Tyagi [23] which aimed at specifying the method used in the evaluation in small, medium \& large sized companies, where the study results showed that many of the industrial sectors such as: petrol industry, pharmacy, iron \& steel, and fertilizer, selected the fundamental analysis for the strategies related to their financial portfolios. As for the modern industrial sectors such as information technology, leisure \& entertainment, communications, mortgages, and feeding, they selected the technical analysis as a strategic tool related to their financial portfolios. Finally, Cohen, et al., [6] explained that in the Israeli capital market there are no significant differences between the specialist and non-specialist investors in using the fundamental and technical investment tools.

The second type depends on an empirical study, in a study by Bettman, et al., [1] was attempted to answer the following question: Is the approach Fundamental and Technical Analysis alternative or complementary? The test proved that the complementary nature of the technical and fundamental analysis shows that despite the fact that both work well separately, when merging the two models, we get less predictive ability stocks value. In a contrast to Bettman, et al., [1] study, it has resulted in Lee \& Shih [12] study that the merged momentum strategy for fundamental and technical information is superior to the technical momentum strategy through obtaining large significant returns for both of the growth and stock value.

In another Study by Neely, et al., [18] was aimed at comparing the fundamental trading models and the technical trading models. The study results concluded that both methodologies provided statistical and economical importance especially concerning the recession in the business cycle, add to the results showed that the fundamental rules of trading is more realistic in predicting the future stock value, but the behavioral effects has a major role in explaining forecasting the stock value over business cycle, which supports the technical analysis profitability. Finally, we find the study of Moosa \& Li [16], which attempted to know which type of trading is more effective in the Chinese Stock Exchange. The results showed that, although both of the methods of technical trading and the fundamental trading, however the trading using the technical analysis is more effective. This is consistent with the findings of the Neely, et al., [18].

\section{vi. Methodology and Models}

In order to test our hypothesis, we have conducted an empirical study and we have covered 37 Non-financial companies between 1998 and 2009, the study started in 1998 to reduce the misleading effects of changes in the accounting rules on the numbers stated in the accounting reports, where the Egyptian Government implemented its new accounting standards on the basis of the International Accounting Standards in year 1997 [21], where this series (1998 - 2009) is divided into two periods followed up Chung \& Kim [5]: The First Period; starts from 1998 until 2006, in order to estimate the forecasting model. The Second Period; is for forecasting the stock value, where it starts from 2007 and 2009.

We consider 2 groups in our analysis. In the first group related to the fundamental analysis which considers 2 models, in the model (1) related to predict stock prices, based on Fung, et al., [10], we can illustrate that:

$$
P_{i, t}=\alpha+\beta_{1} B V P S_{i, t-1}+\beta_{2} E P S_{i, t-1}+\varepsilon_{t}
$$

Where $P_{i, t}$ express the expected closing stock price for company $(i)$, at period $(t), \alpha, \beta_{1}, \beta_{2}$ are mathematical coefficients, $B V P S_{i, t-1}$ consider to Book Value per share in Company $(i)$ at period $(t-1)$ which is calculated as follows: Book Value per share $=$ Shareholders Equity $/$ Number of Shares, $E P S_{i, t-1}$ Earning Per Share to the company $(i)$ at period $(t-1)$, which is calculated using the following equation: Earning Per Share $=$ Net Profit $/$ Number of Traded Shares, and $\varepsilon_{t}$ is Randomized Errors at Time Period $(t)$.

In the model (2) related to predict the stock returns, we propose the following model based on Ragab \& Omran [21], it's shown as:

$$
R_{i, t}=\alpha+\beta_{1} E P S_{i, t-1} / P_{i, t-1}+\varepsilon_{t}
$$

Where $R_{i, t}$ is expected returns of the company $(i)$ over period $(t)$, and $E P S_{i, t-1} / P_{i, t-1}$ ratio of earning per share over the stock price of share for company $(i)$ at period $(t-1)$ where; $E P S_{i, t-1}$ expresses the earning per share, what was previously calculated, $P_{i, t-1}$ expresses the previous annual stock price of company $(i)$ at the end of period $(t-1)$.

On the other side, we consider the second group, related to the technical analysis, which consider 2 models too, so in the model (3) related to predict stock prices, based on Pai \& Lin [20] study, we find that it is possible to use the simple regression model to forecast the future stock prices as follows:

$$
P_{i, t}=\alpha+\beta_{1} P_{i, t-1}+\varepsilon_{i, t}
$$

Where $P_{i, t-1}$ is closing stock price for company $(i)$, over period $(t-1)$.

Final model (4) which related to predict stock returns, according to Li \& Chen [13] and Pai \& Lin [20], we can propose the following regression model as:

$$
R_{i, t}=\alpha+\beta_{1} R_{i, t-1}+\varepsilon_{i, t}
$$

Where, $R_{i, t-1}$ considers the previous stock returns to company (i) at period $(t-l)$. 


\section{Emprical Study}

\section{A. Testing the Study Hypotheses}

We used the Pooled Cross-Sectional \& Time-Series Analysis, because it has advantages, as shown by Blatagi [2] and Brooks [3]. In order overcome a wide range of problems (i. e. Homgeneity, Multicollinearity, and Biases).

\section{1) Testing First Hypothesis}

In $\mathrm{H}_{1}$; states "There is no significant difference between the technical analysis results and the fundamental analysis results concerning the stock price". To achieve this, we follow that methodology followed by Chung \& Kim [5] divided the study period. We find that dividing the study period into two Panels: the first panel; is a testing period and estimate of the forecast model (Panel 1 - Estimation: 1999 2006) ${ }^{1}$. The second period; forecast period of the estimated values (Panel 2 - Prediction: 2007-2009). Then, is followed by a comparison between the forecasted value (estimated) and the market values (Actual), to answer the following question: Is the forecasted value using the fundamental analysis technique by model (1) close to the market value (actual value), or the forecasted value using the technical analysis technique by model (3) nearer to the market value for the share? This is shown as follows:

\section{a) The Estimation Period (1999-2006)}

This period shows testing and estimating two models for forecasting the future stock prices which is shown in Table (I). It shows the statistical indicators that show the models' ability to predict, and to get two models for forecasting future value (stock prices).

TABLE I.

\begin{tabular}{|c|c|c|}
\hline $\begin{array}{c}\text { Results of } \\
\text { estimating models } \\
\text { (Panel 1- } \\
\text { Estimation: 1999_- } \\
\text { 2006) }\end{array}$ & 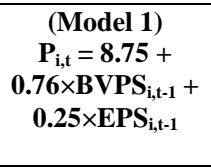 & 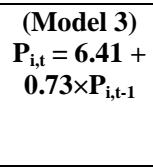 \\
\hline $\begin{array}{c}\text { Intercept } \\
(t \text {-stat })\end{array}$ & $\begin{array}{c}8.745219 \\
(3.183226)^{* * *}\end{array}$ & $\begin{array}{c}6.409193 \\
(4.052546)^{* * *}\end{array}$ \\
\hline $\begin{array}{c}\text { BVPS }_{i, t-1} \\
(t \text {-stat })\end{array}$ & $\begin{array}{c}0.760044 \\
(7.287608)^{* * * *}\end{array}$ & \\
\hline $\begin{array}{c}E^{E P S_{i, t-1}} \\
(t-\text { stat })\end{array}$ & $\begin{array}{c}0.252855 \\
(2.441546)^{* *}\end{array}$ & \\
\hline $\begin{array}{c}P_{i, t-1} \\
(t-s t a t)\end{array}$ & & $\begin{array}{c}0.726235 \\
(19.56662)^{* * *} \\
\end{array}$ \\
\hline $\begin{array}{c}\text { Total panel } \\
\text { (balanced) } \\
\text { observation }\end{array}$ & 296 & 296 \\
\hline R-squared & 0.178986 & 0.565637 \\
\hline Adj. R-squared & 0.173381 & 0.564159 \\
\hline S.E. of Regression & 29.45166 & 21.38558 \\
\hline Sum squared residual & 254148.2 & 1325.567 \\
\hline$F$-statistic & $(31.93781)^{* *+1}$ & $(382.8525)^{\text {***a }}$ \\
\hline
\end{tabular}

Firstly, the results of Table (I) show the results of FStat. test contend that both models get a high degree of precision with a high significance at different significance levels i.e. $(1 \%, 5 \%, 10 \%)$ which corroborates that both models are predictable.

On the other hand, in the table (I) shows better results in favor of the Technical Analysis, where this technique is better than the Fundamental Analysis technique in terms of the Adj. R-squared which equals (56.6\%) relative to (17.3\%) for the Fundamental Analysis Model. Moreover this table shows that the Technical Analysis Model is superior to the Fundamental Analysis Model through the S.E. of Regression less \& the value of the sum squared residuals less too in favor of Technical analysis. This confirms the priority and validity of the Technical Analysis Model compared to the Fundamental Analysis Model when predicting the future stock prices as the consequence of a reduction in the errors resulted from using the Technical Analysis Model.

So, we move on to the second period to test the predictive ability for both models, accordingly, comparing those values (forecasted values) with the corresponding values (Actual Values), to determine which of the two models is more credible.

\section{b) The Foreccasting Period (2007-} 2009)

Using the parameters in the estimated models for each of technique (Fundamental analysis \& Technical analysis), comes the stage of forecasting the future stock prices during the period (2007 - 2009). Consequently, it becomes clear through table (II) for each model as follows:

TABLE II.

\begin{tabular}{|c|c|c|}
\hline $\begin{array}{l}\text { Forecasting Results Using } \\
\text { Prices Models (Panel 2- } \\
\text { Prediction: 2007-2009) }\end{array}$ & 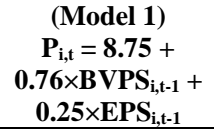 & 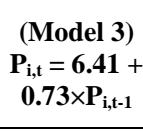 \\
\hline $\begin{array}{l}\text { Total panel (balanced) } \\
\text { observation }\end{array}$ & 111 & 111 \\
\hline $\begin{array}{c}\text { Root Mean Squared Error } \\
(\text { RMSE) }\end{array}$ & 82.53884 & 69.89783 \\
\hline Mean Absolute Error (MAE) & 31.57174 & 29.90413 \\
\hline Bias Proportion & 0.079714 & 0.043768 \\
\hline Variance Proportion & 0.727078 & 0.595007 \\
\hline
\end{tabular}

Table (II) shows that a reduction in the MAE and RMSE indicators for the Technical Analysis (29.90 - 69.89 respectively) compared to the Fundamental Analysis (31.57 - 82.54 respectively) means a reduction in the errors of estimation resulted from the forecasting using the Technical Analysis Model compared with the Fundamental Analysis Model.

The Bias Proportion resulted from using the Technical Analysis (0.049) is less than that resulted from using the Fundamental Analysis Model i.e. (0.079). This indicates the decrease in errors resulting from the estimated values depending on the Technical Analysis Model compared to the Fundamental Analysis. 
We also notice the Variance Proportion resulted from using the Technical Analysis Model equals (0.59) (i.e. is near to Zero), if compared with that result from the Fundamental Analysis which equals (0.73). This shows that the forecasted values are becoming near to the actual values of the Technical Analysis Approach compared to the Fundamental Analysis Approach.

From the above, we conclude that there is significant difference between the Technical Analysis results and the Fundamental Analysis Results concerning the stock price in favor of the technical analysis. So we rejected hypothesis 1 . This can be illustrated by the Fig. 1, considering that the forecasted value using the Fundamental Analysis Model, are referred to by the symbol $\left(P F 1 \_N E W\right)$, and the forecasted value using the Technical Analysis which is referred to using the symbol $\left(P F 2 \_N E W\right)$, and the observed Actual Value (Evaluation Standard), is referred to the Symbol $(P)$, during each time period.

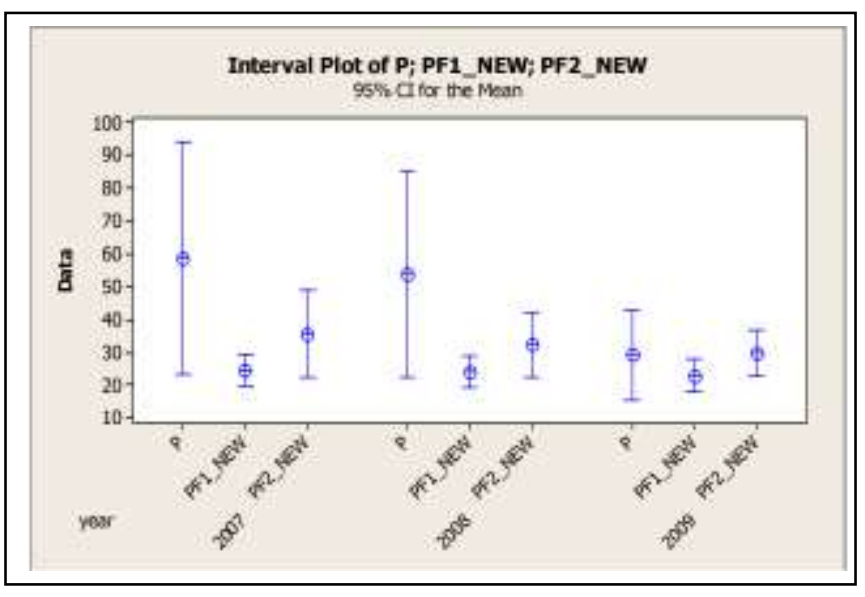

Figure 1. Statistical analysis of the outputs of the E_Views program.

\section{2) The Second Hypothesis}

In $\mathrm{H}_{2}$; states: "There is no significant difference between the Technical Analysis Results and the Fundamental Analysis Results concerning the stock returns". To verify this, we followed the same methodology which was previously followed to test the first hypothesis. Therefore, we see that it is possible to divide the study period into two periods (i.e. Two Panels). The First Period: This is the test period and estimation of the forecast model; (Panel 1 - Estimation: $2000-2007)^{2}$. The Second Period: This is the forecast period of the estimated values; (Panel 2 Prediction: 2008 - 2009). This is followed by the comparison between the forecasted values (estimated) and the market values (Actual), to answer the following question: Is the forecasted value using the fundamental analysis technique by model (2) close to the market value (actual value), or the forecasted value using the technical analysis technique by model (4) nearer to the market value for the share? This is shown as follows:

\section{a) The Estimation Period (2000-2007)}

This Period shows testing and estimating the two forecasting models of the future stock returns. Table (III) shows the statistical indicators which show the potential of the models to forecast and which produce two models for forecasting the future values (Returns).

TABLE III.

\begin{tabular}{|c|c|c|}
\hline $\begin{array}{c}\text { Results of Estimating Models } \\
\text { of forecasting stock returns } \\
\text { (Panel } 1 \text { - Estimation: 2000- } \\
\text { 2007) } \\
\end{array}$ & $\begin{array}{c}\text { (Model 2) } \\
\mathbf{R}_{\mathrm{i}, \mathrm{t}}=0.29- \\
0.21 \times \mathbf{E P S}_{\mathrm{i}, \mathrm{t}-2} / \mathbf{P}_{\mathrm{i}, \mathrm{t}-} \\
2\end{array}$ & $\begin{array}{c}\text { (Model 4) } \\
\mathbf{R}_{\mathrm{i}, \mathrm{t}}=0.22- \\
\mathbf{0 . 1 7 \times} \times \mathbf{R}_{\mathrm{i}, \mathrm{t}-1}\end{array}$ \\
\hline $\begin{array}{c}\text { Intercept } \\
(t \text {-stat })\end{array}$ & $\begin{array}{c}0.286214 \\
(5.550225)^{* * *}\end{array}$ & $\begin{array}{c}0.220540 \\
(4.894537)^{* * * *}\end{array}$ \\
\hline $\begin{array}{c}\operatorname{EPS}_{i, t-2} / \boldsymbol{P}_{i, t-2} \\
(t-s t a t)\end{array}$ & $\begin{array}{c}-0.205173 \\
(-2.034535)^{* *} \\
\end{array}$ & \\
\hline $\begin{array}{c}R_{i, t-1} \\
(t-s t a t)\end{array}$ & & $\begin{array}{c}-.166542 \\
(-2.846457)^{* * *}\end{array}$ \\
\hline $\begin{array}{c}\text { Total panel (balanced) } \\
\text { observation }\end{array}$ & $296^{3}$ & $333^{4}$ \\
\hline R-squared & 0.156305 & 0.259642 \\
\hline Adj. R-squared & 0.1327305 & 0.143558 \\
\hline S.E. of Regression & 0.845306 & 0.811023 \\
\hline Sum squared resid. & 205.0736 & 188.7768 \\
\hline F-statistic & $(6.646307)^{* * 1}$ & $(2.236671)^{* 2}$ \\
\hline
\end{tabular}

The Symbols $(*, * *, * * *)$ show the statistical significance at various significant levels $(1 \%, 5 \%, 10 \%)$ respectively.

Firstly, the results of Table (III) show the results of FStat. test contend that both models get a high degree of precision with a high significance at different significance levels i.e. $(1 \%, 5 \%, 10 \%)$ which corroborates that both models are predictable.

On the other side, this table shows better results in favor of the Technical Analysis where this technique is superior over the Fundamental Analysis technique in terms of the Adj. R-squ. Which equals (14.4\%) against (13.3\%) for the Fundamental Analysis model. That means a relative difference in favor of the Technical Analysis. In addition to other statistical indicators, such as: a reduction in the value of the standard errors of regression in the Technical Analysis Model (0.81) compared to the Fundamental Analysis Model (0.85), also a reduction in the value of the sum squared reside. Resulted from the technical analysis model (188.77) compared to the Fundamental Analysis Model (205.07). These results show the initial superiority of the Technical Analysis Model over the Fundamental Analysis Model. 


\section{b) The Forecasting Period (2008-2009)}

Using the parameters in estimated models for each techniques (Fundamental Analysis \& Technical Analysis), comes the stage of forecasting of the future stock return during the period (2008 - 2009) consequently, it becomes clear through Table (IV), for each model as follows:

TABLE IV.

\begin{tabular}{|c|c|c|}
\hline $\begin{array}{c}\text { Forecasting Results Using } \\
\text { Returns Models (Panel 2 - } \\
\text { Prediction: 2008-2009) }\end{array}$ & $\begin{array}{c}\text { (Model 2) } \\
\mathbf{R}_{\mathrm{i}, \mathrm{t}}=\mathbf{0 . 2 9}- \\
\mathbf{0 . 2 1} \times \mathbf{E P S}_{\mathrm{i}, \mathrm{-2}} / \\
\mathbf{P}_{\mathrm{i}, \mathrm{-}-\mathbf{2}}\end{array}$ & $\begin{array}{c}\text { (Model 4) } \\
\mathbf{R}_{\mathrm{i}, \mathrm{t}}=\mathbf{0 . 2 2}- \\
\mathbf{0 . 1 7} \times \mathbf{R}_{\mathrm{i}, \mathrm{t}-\mathbf{1}}\end{array}$ \\
\hline $\begin{array}{c}\text { Total panel (balanced) } \\
\text { observation }\end{array}$ & 74 & 74 \\
\hline $\begin{array}{c}\text { Root Mean Squared Error } \\
\text { (RMSE) }\end{array}$ & 1.300845 & 1.376090 \\
\hline Mean Absolute Error (MAE) & 0.792116 & 0.802559 \\
\hline Bias Proportion & 0.006094 & 0.000001 \\
\hline Variance Proportion & 0.963690 & 0.551699 \\
\hline
\end{tabular}

As shown in Table (IV), there is a conflict results in each of the (MAE \& RMSE) measure, the quality of forecasted values of the two models with almost equal standard errors. We find that its value for the Fundamental Analysis Model equals $(0.79,1.30)$ respectively. It is considered much less compared to the Technical Analysis Model whose results give measures which are $(0.80,1.38)$ respectively. So it is clear that through these indicators, we cannot confirm any of the trading techniques which are more credible in forecasting the stock returns. As well as in The Bias Proportion stated in Table (IV) shows that the bias proportions are almost equal for each model.

Despite all what stated above, it did no settle the difference between both models to reach which one of them is more credible. In Table (IV), we find that the variance proportion resulted from using the Technical Analysis equals $(0.55)$, which is a small proportion compared to that resulted from using the Fundamental Analysis Model which equals (0.96). This shows the credibility of using the Technical Analysis Method over the Fundamental Analysis.

Based on all what presented above, we can conclude that there is a significant difference between the Technical Analysis results and the Fundamental Analysis results concerning the stock return in favor of the Technical Analysis. So we rejected hypothesis 2. This can be illustrated by the Fig. 2, considering that the forecasted value using the Fundamental Analysis Model, are referred to using the symbol $\left(R F 1 \_N E W\right)$, and the forecasted value using the Technical Analysis which is referred to using the symbol $\left(R F 2 \_N E W\right)$, and the Actual Observed Value (Evaluation Standard), is referred to the Symbol $(R)$, at each time period.

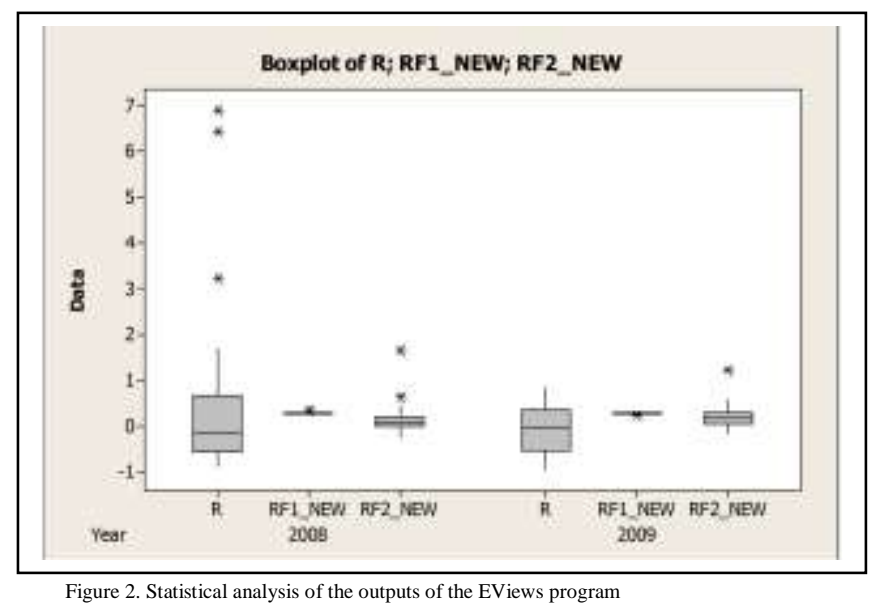

\section{vIII. Findings and Conclusion}

The findings of this study reveal the following points:

A. The Credibility of results produced by the Technical Analysis Method in forecasting the future stock prices compared to the results of forecasting using the Fundamental Analysis Method.

B. The Credibility of the results of the Technical Analysis Method in forecasting the future stock returns compared to the results of forecasting using the Fundamental Analysis Method.

Despite the fact that the results support the Technical Analysis Method in its ability to forecast the future value of the share (prices or returns), it also matched the previous studies, which aimed at comparison of both methods, but this results prove that there are defects in information, and inefficient financially in the Egyptian Stock Exchange. Furthermore the financial information do not reflect the value of the share (prices or returns) - as expressed by the Fundamental Analysis concept - There are due many reasons from the point of view of this study as follows:

1. Scarcity of information and its financial efficiency, the consequence of non-presence of financial efficiency in the Egyptian stock exchange. This agrees with many studies which were applied in the Egyptian Market such as [21].

2. Large variations in the issue of reports and financial statements about the financial companies listed in the Egyptian Stock Exchange, and a delay in making that information available for all (investors and researchers). This is considered as a defect in one of the efficiency conditions, which include making information and data available simultaneously for those of interest.

3. The influence of the non-economic reasons (political, social, behavior, .... etc) in the Egyptian stock exchange, which is outside the scope of this study. This reason is seen as the consequence of the theoretical study, whose influence is reflected on the results of the current applied study. 


\section{References}

[1] L. J. Bettman, J. S. Sault, , and L. E. Schultz, "Fundamental and Technical analysis: Substitutes or complements?" Accounting and finance, Vol. 49, No. 1, pp. 21-36, 2009.

[2] B. H. Blatagi, "Econometric Analysis of Panel Data," 3rd ed.., John Wiley and Sons, Ltd, West Sussex, 2005.

[3] C. Brooks, "Introductory Econometrics for Finance," 2nd ed., Cambridge University Press, UK, 2008.

[4] J. Chen, "Essentials of Technical Analysis for Financial Markets," John Wiley \& sons, Inc, 2010.

[5] H. Y. Chung, and J. B. Kim, "A structured financial statement analysis and the direct prediction of stock prices in Kore," Asia Pacific Financial Markets, Vol. 8, No. 2, pp. 87-117, 2001.

[6] G. Cohen, A. Kudryavtsev, and S. S. Hon, "Stock market analysis in practice: ISIT technical or fundamental?" Journal of Applied Finance \& Banking, Vol. 1, No. 3, pp. 125-138, 2011.

[7] D. Edwards, and J. Magee, "Technical analysis of stock trends," 9th ed, CRC press, (Bassetti, W. H. C. editors), 2007.

[8] E. Faerber, (2008). "All about stocks," 3rd ed, Mc Grow Hill, 2008.

[9] A. G. Fontanills, and T. Gentile, "The stock Market Course,".John Wiley and Sons,Inc, 2001.

[10] S. Y. Fung, L. N. Su, and X. K. Zhu, "Price Divergence from Fundamental Value and The Value Relevance of Accounting Information," Contemporary Accounting Research, Vol. 27, No. 3, pp. 829-854, 2010.

[11] N. Goumatianos, "improving government's retirement plan investments by using mining tools for discovery of price patterns and combining methods of fundamental and technical analysis", Master Thesis, Navel postgraduate School, Monterey, California, 2008.

[12] F. C. Lee, and K. W. Shih, "Technical, fundamental, and combined information for separating winners from losers," Working Paper Series, Available at SSRN, 15 April. 2010: http://papers.ssrn.com/sol3/papers.cfm?abstract_id=1590460, viewed in 10 Sep 2012.

[13] X. M. Li, and K. J. Chen, "On the Vale of Technical Analysis for Stock Traders in China," Working Paper No. 03.03, Available at SSRN, 2003: http://papers.ssrn.com/sol3/papers.cfm?abstract_id=503782, Viewed in 30 Oct 2012.

[14] A. W. Lo, H. Mamaysky, and J. Wang, "Foundation of Technical Analysis: Compatational Algoriths, Statistical Inference, and Empirical Implementation," The Journal of Finance, Vol. LV, No. 4, pp. 1705-1765, 2000.

[15] Y. H. Lui, and D. Mole, "The use of fundamental and technical analysis by foreign exchange dealers, Hong Kong evidence," Journal of International Money and Finance, Vol. 17, No. 3, pp. 535-545, 1998.

[16] I. Moosa, and L. Li, "Technical and fundamental trading in the Chinese stock market: Evidence based on time-series and panel data," Emerging Markets Finance \& Trade, Vol. 47, No. 1, pp. 23-31, 2011.

[17] J. Murphy, "Technical Analysis of the financial markets," New York Institute of Finance, 1999.

[18] J. C. Neely, E. D. Rapach, J. Tu, and G. Zhou, "Out-of-sample equity premium prediction: Fundamental vs. Technical analysis," Research collection Lee Kong Chain School of Business (Open Access) paper No. 3063, 2010, Available at: http://ink.library.smu.edu.sg/cgi/viewcontent.cgi?article=4062\&conte $\mathrm{xt}=1 \mathrm{kcsb}$ _research, Viewed 10 Sep 2012.

[19] T. Oberlerchner, "Importance of technical and fundamental analysis in the European foreign exchange market," International Journal of Finance and Economics, Vol. 6, No. 1, pp. 81-93, 2001.

[20] F. P. Pai, and S. C. Lin, "A hybrid ARIMA and support vector machines model in stock price forecasting," The International Journal of Management Science, Vol. 33, No. 6, pp. 497-505, 2005.

[21] A. A. Ragab, and M. M. Omran, "Accounting information, value relevance, and investors' behavior in the Egyptian equity market," Review of Accounting and Finance, Vol. 5, No. 3, pp. 279-297, 2006.

[22] C. M. Thomsett, "Getting started in Fundamental Analysis," John Wiley andSons Inc, 2006.

[23] C. K. Venkatesh, and M. Tyagi, "Fundamental analysis as a method of share valuation comparison with technical analysis," Bangladesh Research Publication Journal, Vol. 5, No. 3, pp. 167-174, 2011.

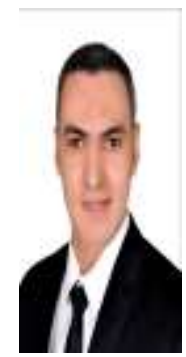

Ahmed S. Wafi received his MSc degree in Finance from the Faculty of Commerce at The Cairo University, Egypt in 2013. Since Nov. 2013, he has been an assistant lecturer with Business Administration department. His research interests involve mainly Security Analysis, Capital Market, Behavioral Finance and Valuation.

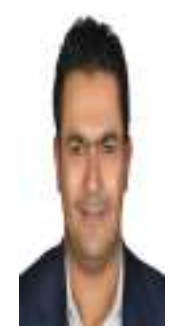

Hassan Hassan received his PhD degree in Finance from the University of Aberdeen, UK, in 2010. Since 2010, he has been a lecturer with Business Administration department. His research interests involve mainly Security Analysis, Behavioral Finance and Islamic Finance.

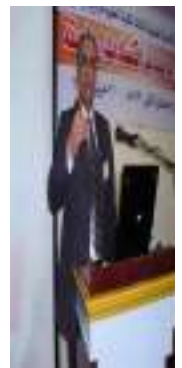

Adel Mabrouk Professor in Finance in Faculty of Commerce, Cairo University and supervised on many theses in Business administration \& Finance. He has been Dean of Faculty of Commerce, Cairo University between 2009 and 2012. Now he is working a professor in Finance in Akhbar El Yom Academy, 6th October City, Egypt. 